\title{
Awareness about rural women regarding health benefit of calcium and risk of osteoporosis
}

\author{
HEMANGI D. MEHTA AND RINA RENSIYA
}

Received: 28.10.2016; Revised: 19.11.2016; Accepted: 25.11.2016

Author for Correspondence :

\section{HEMANGI D. MEHTA}

Polytechnic in Home Science, Junagadh

Agricultural University, AMRELI

(GUJARAT) INDIA

Email : hemangidmeht@gmail.com
ABSTRACT : The natural aging process can cause calcium deficiency disease. Most of the calcium in your body is stored in your bones. Women need to increase their calcium intake earlier in life than men, starting in middle age. Meeting the necessary calcium requirement is particularly important as a woman approaches menopause. Women in menopause should also increase their calcium intake to reduce the risk of osteoporosis and calcium deficiency disease. The decline in the hormone estrogen during menopause causes a woman's bones to thin faster. The hormone disorder hyperparathyroidism may also cause calcium deficiency disease. Many women living in rural communities with high osteoporosis prevalence underestimate their risk of osteoporosis, lack basic knowledge about osteoporosis prevention, and exercise less than recommended. Sometimes diet changes and aware to women for calcium sources.

KEY WORDS: Bones, Osteoporosis, Calcium, Dairy products, Dietary habits

- HOW TO CITE THIS PAPER : Mehta, Hemangi D. and Rensiya, Rina (2016). Awareness about rural women regarding health benefit of calcium and risk of osteoporosis. Asian J. Home Sci., 11 (2) : 446-449, DOI: 10.15740/HAS/AJHS/11.2/446-449. 